\title{
Uptake and Attitudes About Immunizations in People With Multiple Sclerosis
}

Ruth Ann Marrie, MD, PhD, Leanne Kosowan, MSc, Gary R. Cutter, PhD, Robert Fox, MD, MSc, and Amber Salter, PhD

Neurology: Clinical Practice August 2021 vol. 11 no. 4 327-334 doi:10.1212/CPJ.0000000000001099
Correspondence

Dr. Marrie

rmarrie@hsc.mb.ca

Abstract

\section{Objective}

By surveying a multiple sclerosis (MS) population, we tested the hypothesis that influenza vaccine uptake would not meet public health targets and that vaccine misconceptions would contribute to lower than desired uptake.

\section{Methods}

In spring 2020, we surveyed participants in the North American Research Committee on Multiple Sclerosis Registry regarding vaccinations. Participants reported whether they had received hepatitis A, hepatitis B, pneumococcal, shingles, varicella, measles/

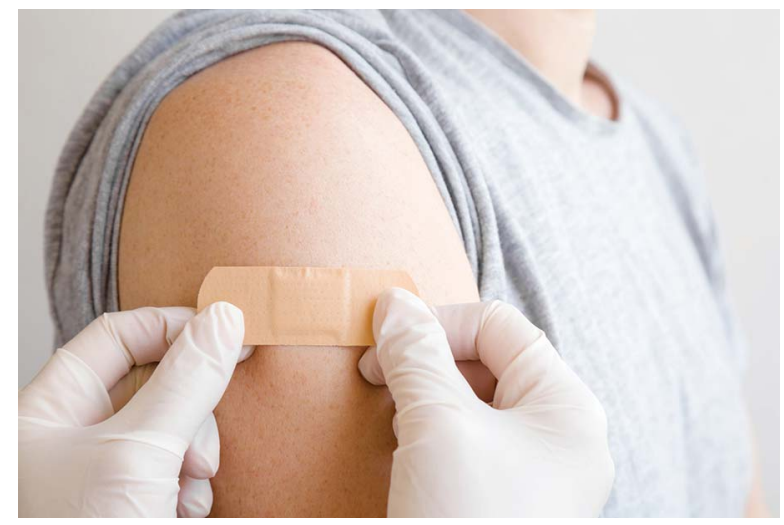
mumps/rubella, tetanus, or influenza vaccines. Participants who had not received influenza vaccine last year reported the reasons. We summarized responses descriptively. Using multivariable logistic regression, we assessed participant characteristics associated with uptake of seasonal influenza vaccine.

\section{Results}

Of 5,244 eligible respondents, $80.8 \%$ were female, with a mean (SD) age of 61.8 (10.1) years. Overall, $43.0 \%(2,161 / 5,032)$ of participants reported that their neurologist had ever asked about their immunization history. The percentage of participants who received the seasonal flu vaccine last year ranged from $59.1 \%$ among those aged $18-24$ years to $79.9 \%$ for persons aged $\geq 65$ years. Among those who did not get the influenza vaccination, the most common reasons were personal preference (29.6\%), concerns about possible adverse effects in general $(29.3 \%)$, and concerns that the vaccine would worsen their MS (23.7\%).

\section{Conclusion}

Vaccination uptake is lower than desired in the MS population compared with existing recommendations, including for seasonal influenza. Misconceptions about the safety of vaccination in the context of MS and personal preference appear to play important roles in vaccination choices, highlighting the importance of education about these issues.

Individuals with multiple sclerosis (MS) have an elevated risk for infection compared with individuals without $\mathrm{MS}^{1,2}$ and an elevated risk for postinfectious complications. For example, individuals

Departments of Internal Medicine and Community Health Sciences (RAM), Max Rady College of Medicine, Rady Faculty of Health Sciences, University of Manitoba, Winnipeg Canada Department of Family Medicine Max Rady College of Medicine (LK), Rady Faculty of Health Sciences, University of Manitoba, Winnipeg, Canada; Department of Biostatistics (GRC), University of Alabama at Birmingham, AL; Mellen Center for Multiple Sclerosis (RF), Neurological Institute, Cleveland Clinic, OH; and Department of Biostatistics (AS), Washington University in St. Louis, MO.

Funding information and disclosures are provided th the end of the article. Full disclosure form information provided by the authors is available with the full text of this article at Neurology.org/cp.

The Article Processing Charge was funded by the Consortium of Multiple Sclerosis Centers.

This is an open access article distributed under the terms of the Creative Commons Attribution-NonCommercial-NoDerivatives License 4.0 (CC BY-NC-ND), which permits downloading and sharing the work provided it is properly cited. The work cannot be changed in any way or used commercially without permission from the journal. 
with MS are more likely to be hospitalized and die of influenza than individuals without MS. ${ }^{2}$ Influenza infection also increases relapse risk. $^{3}$ Several potentially serious infections, including influenza, can be prevented by vaccination. Vaccinations are of increasing concern as stronger immunomodulating therapies are used more widely for MS management, as these therapies may influence the need for and safety of vaccinations. Recent guidelines from the American Academy of Neurology focused on vaccinations, ${ }^{4}$ and the COVID-19 pandemic has heightened interest in vaccines in people living with MS.

Few studies have evaluated vaccination uptake in the MS population, and most have focused on influenza. ${ }^{5}$ In Israel, only onethird of respondents reported receiving seasonal flu vaccine in 2009-2010. In Manitoba, Canada, fewer than $40 \%$ of persons with MS received the influenza vaccine in $2015 .{ }^{6}$ In other populations with immune-mediated diseases, general and diseasespecific barriers to vaccination have been reported, ${ }^{7}$ but relevant barriers in the MS population have not been reported. We aimed to determine uptake of seasonal influenza vaccine in a large sociodemographically diverse MS population, to investigate reasons for not obtaining the vaccine, and to determine lifetime uptake of other common vaccinations. We hypothesized that influenza vaccine uptake would not meet public health targets and that vaccine misconceptions would contribute to lower than desired uptake.

\section{Methods}

\section{Study Population}

The North American Research Committee on Multiple Sclerosis (NARCOMS) Registry is a self-report registry for persons with MS. ${ }^{8}$ At enrollment, participants report sociodemographic and clinical information, which is updated semiannually via survey. Surveys are completed either on paper or online.

\section{Standard Protocols, Approvals, and Participant Consents}

Participants permit use of their deidentified information for research purposes. At the time of the spring 2020 survey, the NARCOMS Registry was approved by the Institutional Review Board of Washington University at St. Louis.

\section{Participant Characteristics}

For this study, we used information from the enrollment and spring 2020 questionnaires. The information obtained from the enrollment questionnaire included birth date, sex, race, education level, region of residence, and ages at MS symptom onset and diagnosis. We categorized race as White or non-White. We categorized education level as high school/General Educational Development certificate and postsecondary (associate's degree, bachelor's degree, postgraduate education, and technical degree).

We obtained all the remaining information from the spring 2020 questionnaire, including annual household income, marital status, health behaviors, and disability status. Annual household income was reported as $\leq \$ 50,000, \$ 50,001-\$ 100,000$, $>\$ 100,000$, and "I do not wish to answer." We categorized marital status as single (never married, divorced, widowed, or separated) and married (married or cohabiting). Health behaviors captured included smoking status, physical activity, and alcohol intake. Participants reported their current smoking status as no, yes some days, or yes every day, using a question from the Behavioral Risk Factor Surveillance Survey; we aggregated these responses to yes/no. ${ }^{9}$ They reported whether they had participated in any physical activity or exercise during the past month (yes/no). Participants also reported alcohol intake using 1 question from the Alcohol Use Disorders Identification Test. ${ }^{10}$ We modified the question to ask about alcohol intake over the past 6 months instead of the past 12 months. Response options were never, monthly or less, 2 to 4 times a month, 2 to 3 times a week, or 4 or more times a week.

Disease duration from symptom onset was categorized $(<10$, $10-19$, and $\geq 20$ years). Participants reported disability status using Patient Determined Disease Steps (PDDS), a single-item measure with response options ranging from 0 (normal) to 8 (bedridden). The PDDS correlates strongly with a physicianscored Expanded Disability Status Scale score. ${ }^{11}$ For this analysis, we categorized PDDS as mild (0-1), moderate (2-4), and severe (5-8). ${ }^{12}$ Based on the relevant items from SymptoMScreen, we classified participants as having any depression (yes/no) or anxiety (yes/no) symptoms. ${ }^{13}$ Participants reported use of disease-modifying therapies (DMTs) in the last 6 months. We grouped these as none or any.

\section{Immunization}

Participants reported whether their neurologist had ever asked about their immunization/vaccination history (yes, no, or don't know) and who they thought was responsible for determining which vaccinations they should receive (neurologist, primary care physician, participant, and other; multiple options were allowed). ${ }^{14}$ Participants were asked to report whether they had ever received vaccines for any of the following: hepatitis A, hepatitis B, pneumococcal, shingles, varicella, measles/mumps/rubella, and tetanus, where responses were yes, no, or don't know. For all vaccines except influenza, the time frame was ever receipt of the vaccine. We did not distinguish types of pneumococcal or zoster vaccines to avoid potential confusion by participants.

For influenza, we focused on the most recent influenza season to better assess current behaviors and attitudes. We adapted a questionnaire previously used in persons with inflammatory bowel disease (IBD). ${ }^{15}$ Participants who indicated that they had not received an influenza vaccine were asked to mention the reason, with potential responses being (1) never offered; (2) did not think I needed it; (3) allergy to eggs/vaccine; (4) concerned about side effects from the vaccine; (5) too expensive; (6) too busy/forgot; (7) my doctor advised against a flu shot; (8) concerned that the vaccine would worsen my MS; (9) vaccine not available; and (10) other (specify). Finally, participants were asked whether their neurologist had advised them to avoid certain vaccines and, if yes, to indicate which ones-the choices were the same as described earlier. 
Table 1 Clinical and Demographic Characteristics of Study Participants

\begin{tabular}{ll}
\hline Characteristics & $\begin{array}{l}\text { Participants } \\
\mathrm{N}=5,244\end{array}$ \\
\hline $\begin{array}{l}\text { Age at the time of spring } 2020 \text { survey (y), mean } \\
\text { (SD) }\end{array}$ & $61.8(10.1)$ \\
\hline Age group (y), $\mathbf{n}(\%)$ & $46(0.9)$ \\
\hline $\mathbf{1 8 - 3 4}$ & $557(10.6)$ \\
\hline $\mathbf{3 5 - 4 9}$ & $2,448(46.7)$ \\
\hline $\mathbf{5 0 - 6 4}$ & $2,187(41.8)$ \\
\hline $\mathbf{6 6 5}$ & $4,235(80.8)$ \\
\hline Female, $\mathbf{n}(\%)$ & $4,581(87.4)$ \\
\hline White race, $\mathbf{n}(\%)$ &
\end{tabular}

Education at enrollment, $\mathbf{n}(\%)$

\begin{tabular}{lc}
\hline High school/GED & $1,372(26.2)$ \\
\hline Postsecondary & $3,749(71.5)$ \\
\hline
\end{tabular}

Annual household income at enrollment, $\mathrm{n}(\%)$

\begin{tabular}{ll}
\hline Less than $\mathbf{\$ 5 0 , 0 0 0}$ & $1,681(32.1)$ \\
\hline $\mathbf{\$ 5 0 , 0 0 1 - \$ 1 0 0 , 0 0 0}$ & $1,277(24.4)$ \\
\hline Over $\mathbf{\$ 1 0 0 , 0 0 0}$ & $1,018(19.4)$ \\
\hline I do not wish to answer & $1,117(21.3)$ \\
\hline Age at MS symptom onset (y), mean (SD) & $31.9(9.6)$ \\
\hline Age at MS diagnosis (y), mean (SD) & $39.1(9.7)$ \\
\hline Disease duration (y), mean (SD) & $29.9(11.6)$ \\
\hline PDDS, median (IQR) & $4(5)$
\end{tabular}

\begin{tabular}{ll}
\hline PDDS, $\mathbf{n}(\%)$ & \\
\hline Mild (0-1) & $1,522(29.0)$ \\
\hline Moderate (2-4) & $1,668(31.8)$ \\
\hline Severe (5-8) & $1,951(37.2)$ \\
\hline Any disease-modifying therapy in last $\mathbf{6 ~ m o , ~} \mathbf{n}(\%)$ & $2,334(44.6)$ \\
\hline Current smoker, $\mathbf{n}(\%)$ & $270(5.1)$ \\
\hline Leisure activity, $\mathbf{n}(\%)$ & $2,896(55.2)$ \\
\hline Alcohol intake, $\mathbf{n}(\%)$ & $1,852(35.3)$ \\
\hline Never & $1,315(25.1)$ \\
\hline Monthly or less & $772(14.7)$ \\
\hline 2-4 times a month & $539(10.3)$ \\
\hline 2-3 times a week & $668(12.7)$ \\
\hline 24 times a week & $2,911(55.5)$ \\
\hline Anxiety, $\mathbf{n}$ (\%) & $3,114(59.4)$ \\
\hline Depression, $\mathbf{n}(\%)$ & \\
\hline
\end{tabular}

Abbreviations: IQR = interquartile range; MS = multiple sclerosis; PDDS = Patient Determined Disease Step.

\section{Statistical Analysis}

We excluded individuals who did not report a confirmed diagnosis of MS, sex, or date of birth; those who did not live in the United States to reduce heterogeneity due to differences in health system delivery in other countries; and those with an age at symptom onset $<16$ years. Missing responses were not imputed.

First, we used descriptive statistics to summarize the characteristics of the respondents using means (SD), median (interquartile range), and frequency (percent) and their responses to the vaccination questions. Second, we summarized uptake of each vaccine queried overall and stratified by sex, age (18-34, 35-50, 51-64, and $\geq 65$ years), disability status (mild, moderate, and severe), and DMT use (no as reference). Third, we summarized the reasons for not receiving influenza vaccine.

Finally, we examined factors associated with the uptake or nonuptake of the influenza vaccination using binary logistic regression. The models included sex (female as the reference group), age ( $\geq 65$ years as the reference group), disease duration ( $<10$ years as reference), race (White as reference), education level (high school as reference), income $(<\$ 50,000$ as reference), current smoking status (no as reference), alcohol intake (never as reference), physical activity (inactive as reference), disability status (mild as reference), DMT use, depression (no as reference), and anxiety (no as reference). We used standard methods to assess model assumptions and assessed model fit using the Hosmer-Lemeshow goodness of fit statistic. ${ }^{16}$ We report the C-statistic for each model. Statistical analyses were conducted using SAS V9.4 (SAS Institute Inc., Cary, NC).

\section{Data Availability}

The data sets generated and analyzed during this study are held by the NARCOMS Registry (narcoms.org).

\section{Results}

The spring 2020 survey was distributed to 10,210 participants, of whom 6,385 (62.5\%) responded. Compared with nonresponders, responders were more likely to be White ( $86.7 \%$ vs $82.6 \%, p<0.001)$, female $(80.9 \%$ vs $78.7 \%, p=$ 0.009 ), older (62.0 vs 59.0 years), and with a higher level of education (postsecondary $72.7 \%$ vs $68.9 \%, p<0.001$ ). However, most of these differences were statistically different but not clinically meaningful. After applying exclusion criteria, 5,244 participants constituted the final sample (figure e1, links.lww.com/CPJ/A292). Most participants were aged $\geq 51$ years, White, and female, with moderate or severe disability (table 1).

\section{Vaccination Uptake}

Of the vaccinations queried, the most commonly received were tetanus, followed by measles, mumps, rubella (MMR), 
Table 2 Lifetime Uptake of Vaccines ( $\mathrm{n}, \%)$

\begin{tabular}{lllll}
\hline Vaccine & Yes & No & Don't know & Missing \\
\hline Tetanus & $4,305(88.5)$ & $367(7.6)$ & $191(3.9)$ & 375 \\
\hline MMR & $3,523(74.1)$ & $835(17.6)$ & $394(8.3)$ & 486 \\
\hline Influenza shot $^{\mathrm{a}}$ & $3,766(74.1)$ & $1,303(25.6)$ & $15(0.3)$ & 154 \\
\hline Pneumonia & $2,958(61.2)$ & $1,600(33.1)$ & $275(5.7)$ & 405 \\
\hline Varicella & $1,909(42.1)$ & $2,120(46.7)$ & $508(11.2)$ & 701 \\
\hline Herpes zoster & $1,904(41.2)$ & $2,483(53.7)$ & $236(5.1)$ & 615 \\
\hline Hepatitis B & $1,464(32.3)$ & $1,950(43.0)$ & $1,126(24.8)$ & 698 \\
\hline Hepatitis A & $984(22.0)$ & $2,228(49.7)$ & $1,268(28.3)$ & 758 \\
\hline
\end{tabular}

Abbreviation: $\mathrm{MMR}=$ measles, mumps, rubella.

For influenza, we asked about vaccination in the most recent influenza season rather than over a lifetime.

and the flu shot (table 2). Vaccination uptake varied by age, and these age-related patterns differed by vaccine (figure 1). The percentage of participants who received the seasonal flu vaccine last year increased with age, reaching $79.9 \%$ for persons aged $\geq 65$ years. Uptake of zoster (59.1\%) and pneumonia (84.7\%) vaccines was also highest among the oldest age group, consistent with the indications for those vaccines. However, the reverse pattern was observed for hepatitis $\mathrm{A}$ and $\mathrm{B}$ vaccinations, where the highest uptake was among those aged 18-34 years (hepatitis A: 93.9\%, hepatitis B: $100 \%)$. We observed less variation in vaccination uptake according to disability status (figure e2, links.lww.com/CPJ/ A292). Overall, $43.0 \%(2,161 / 5,032)$ of participants reported that their neurologist had ever asked about their immunization history, $39.1 \%$ indicated that they had not been asked, and $18.0 \%$ were uncertain.

\section{Factors Associated With Receiving Influenza Vaccination}

On univariate logistic regression, several demographic factors and health behaviors were associated with the likelihood of influenza vaccination. Compared with persons aged $\geq 65$ years, those younger than 65 years had lower odds of being vaccinated (table 3). Postsecondary rather than high school education, a higher level of annual household income, a higher level of alcohol intake, being physically active, and using any DMT were also associated with increased odds of being vaccinated. In contrast, being male, symptoms of depression or anxiety, and currently smoking were associated with reduced odds of being vaccinated. Race, disability status, and disease duration were not associated with being vaccinated.

On multivariable analysis, postsecondary education, household income $>\$ 100,000$ vs $<\$ 50,000$ remained associated with increased odds of being vaccinated. Compared with no alcohol intake, alcohol intake 2-4 times per month was associated with increased odds of being vaccinated, as was physical activity.
Younger age and currently smoking continued to be associated with reduced odds of being vaccinated. Sex and symptoms of depression or anxiety were no longer associated with the odds of being vaccinated. Of MS characteristics, only use of a DMT was associated with vaccination. Participants reporting any use of a DMT had $41 \%$ increased odds of receiving influenza vaccination.

\section{Attitudes Regarding Influenza Vaccination}

Of the 1303 participants who did not get the influenza vaccination in the last flu season and who reported their reasons for not doing so, the most common reasons were related to personal preference $(29.6 \%)$ and concerns about possible adverse effects in general (29.3\%), followed closely by concerns that the vaccine would worsen their MS (23.7\%) (table 4). The personal preference category was dominated by the perception that the individual did not need it (339/391, $86.7 \%)$. However, misconceptions that the influenza vaccine (by injection) was contraindicated with several diseasemodifying therapies were also reported.

When asked who is responsible for determining what vaccinations you should receive, two-thirds of participants responded themselves $(2,659,66.9 \%)$, followed by their primary care providers $(2,302,57.9 \%)$ and their neurologists $(1,636,41.2 \%)$. A very small percentage of participants indicated that someone other than these 3 choices was responsible $(88,2.2 \%)$. Advice to avoid particular vaccines was infrequent, being reported most often for Zoster (362, 6.9\%), followed by influenza nasal mist $(287,5.5 \%)$, other (273, $5.2 \%)$, influenza shot $(132,2.5 \%)$, pneumonia $(76,1.5 \%)$, varicella $(48,0.9 \%), \operatorname{MMR}(39,0.7 \%)$, hepatitis $(24,0.5 \%)$, and tetanus $(14,0.3 \%)$.

\section{Discussion}

In this large cross-sectional study, we found that in the most recent fall/winter season, multiple demographic factors and health behaviors were associated with the likelihood of receiving an influenza vaccination, including age, higher level of education, higher level of income, smoking, and physical activity. Only one of the MS characteristics we examined, use of a disease-modifying therapy, was associated with receiving an influenza vaccination. Among those who did not receive a vaccination, half had concerns regarding adverse effects and misconceptions about the possible impact of the vaccine on their MS. Although these were infrequent, access issues were also reported. Uptake of the other vaccinations queried varied substantially with age.

The most recent American Academy of Neurology guidelines recommend that people with MS follow all local vaccine standards unless there is a specific contraindication and receive the influenza vaccination annually unless there is a specific contraindication. ${ }^{9}$ In the United States, tetanus vaccination is recommended for all adults every 10 years. Vaccination to prevent shingles is recommended for all adults aged $\geq 50$ years; and pneumococcal vaccine is recommended for all adults aged 


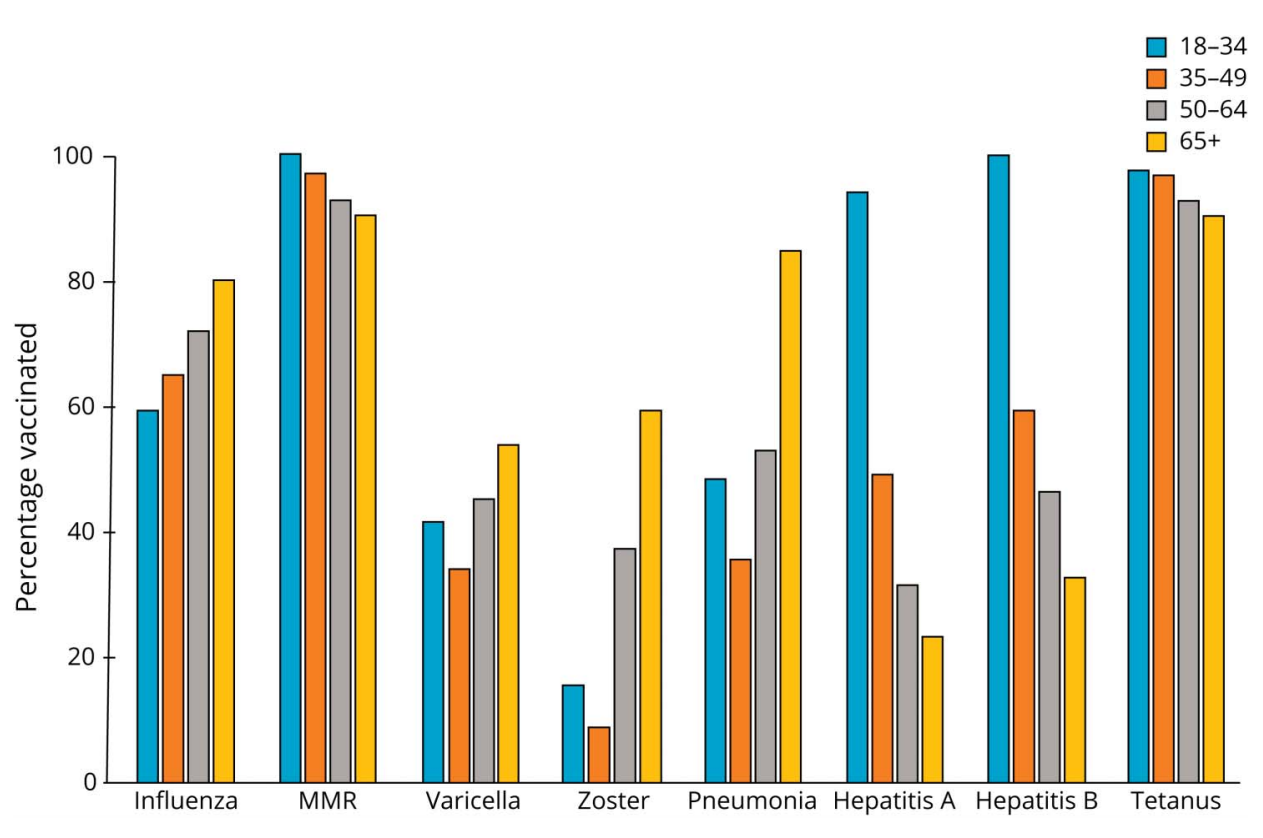

$\geq 65$ years, and for immunocompromised adults aged $\geq 19$ years. These targets were not met among our study participants even when we considered the age-specific nature of some of these recommendations.

In the 2018-19 season, $39.0 \%$ of US adults aged $18-64$ years received the influenza vaccine, whereas $68.1 \%$ of adults aged 65 years and older received the vaccine. ${ }^{17}$ This appears lower than among our participants. However, uptake was higher among adults with high-risk conditions than among adults without high-risk conditions, possibly due to more frequent health system contacts. In other immune-mediated diseases such as IBD, uptake reportedly ranges from $6 \%$ to $80 \%{ }^{7}$ and in rheumatoid arthritis varies from $26.6 \%$ to $85 \% .^{18,19}$ Comparable prior work regarding uptake of immunizations in people with MS is limited, focusing mainly on influenza vaccination. A Norwegian immunization register-based study reported that of 6,755 persons with $\mathrm{MS}, 60.7 \%$ received the pandemic (H1N1) vaccine in $2009-2010 .^{20} \mathrm{~A}$ study of 101 persons with MS followed in Tel Aviv, Israel, found that $37.6 \%$ of participants received the seasonal flu vaccine in $2009 / 10$, and $34.7 \%$ received the H1N1 flu vaccine, whereas $23.7 \%$ received both vaccines. ${ }^{5}$ A recent population-based study in Manitoba, Canada, found that approximately $40 \%$ of persons with MS received an influenza vaccination in 2015. Similar to our findings in the NARCOMS cohort, the uptake of the influenza vaccine was highest among those aged $\geq 65$ years at $60 \%{ }^{6}$

We found that several factors were associated with uptake of the influenza vaccine. In the Manitoba, Canada, study, older age, higher socioeconomic status, and use of disease-modifying therapies were associated with increased uptake of the vaccine by people with MS, consistent with our findings. ${ }^{6}$ In contrast to our findings showing that sex was not associated with uptake, that study also found that female sex was associated with increased uptake. Another study showed that a postsecondary education and being female are associated with greater awareness of vaccine-preventable diseases. ${ }^{21}$

About 1 in 2 participants who did not get seasonal influenza vaccine reported a fear of general adverse effects or of adverse effects on their MS as the reason. One in 10 was advised against getting a flu shot by their physicians. Multiple factors may contribute to the decision not to get a vaccine, but these findings highlight important misconceptions about influenza vaccination and MS among patients and physicians. In the aforementioned Israeli study, the influenza vaccines were well tolerated. Only 5/49 participants who received at least 1 vaccine reported fever or flu-like symptoms, and no neurologic symptoms occurred after receiving vaccine. ${ }^{5}$ There is no convincing evidence that influenza vaccination causes exacerbations of MS. ${ }^{9}$ The inactivated influenza shot is not contraindicated, even in persons with MS who receive immunosuppressive therapies. Although the response to vaccination may be attenuated in individuals taking some therapies, $^{22-25}$ some benefit may still be achieved. Our findings are generally concordant with those in other populations. In a 2015/2016 survey of the Canadian general population, commonly reported reasons for not getting the influenza vaccine included a lack of perceived susceptibility to influenza, lack of perceived severity of infection, and not believing in the vaccine's effectiveness. ${ }^{26}$ In populations with immune-mediated diseases other than MS, additional factors cited include not receiving information about vaccination from a physician, concerns about adverse effects, lack of 
Table 3 ORs ( $95 \%$ Cls) for the Association Between Participant Characteristics and Receipt of the Influenza Vaccination $(n=4,697)$

\begin{tabular}{|c|c|c|}
\hline Characteristic & $\begin{array}{l}\text { Unadjusted OR } \\
(95 \% \mathrm{Cl})\end{array}$ & $\begin{array}{l}\text { Adjusted OR } \\
(95 \% \mathrm{CI})\end{array}$ \\
\hline \multicolumn{3}{|l|}{ Sex } \\
\hline Male & 1.0 & 1.0 \\
\hline Female & $0.81(0.68-0.95)$ & $0.88(0.73-1.05)$ \\
\hline \multicolumn{3}{|l|}{ Age group (y), n (\%) } \\
\hline $18-34$ & $0.36(0.20-0.67)$ & $0.29(0.14-0.60)$ \\
\hline $35-49$ & $0.47(0.38-0.57)$ & $0.35(0.27-0.45)$ \\
\hline $50-64$ & $0.64(0.56-0.74)$ & $0.57(0.49-0.66)$ \\
\hline $65+$ & 1.0 & 1.0 \\
\hline \multicolumn{3}{|l|}{ Race } \\
\hline Non-White & 1.0 & 1.0 \\
\hline White & $1.00(0.82-1.20)$ & $1.12(0.92-1.38)$ \\
\hline \multicolumn{3}{|l|}{ Education } \\
\hline High school/GED & 1.0 & 1.0 \\
\hline Postsecondary education & $1.43(1.24-1.64)$ & $1.26(1.08-1.47)$ \\
\hline \multicolumn{3}{|l|}{ Annual household income } \\
\hline Less than $\$ 50,000$ & 1.0 & 1.0 \\
\hline$\$ 50,001-\$ 100,000$ & $1.23(1.04-1.45)$ & $1.07(0.89-1.28)$ \\
\hline Over $\$ 100,000$ & $1.58(1.31-1.90)$ & $1.44(1.16-1.79)$ \\
\hline I do not wish to answer & $1.27(1.06-1.51)$ & $1.11(0.92-1.34)$ \\
\hline \multicolumn{3}{|l|}{ Current smoking status } \\
\hline No & 1.0 & 1.0 \\
\hline Yes & $0.51(0.41-0.64)$ & $0.60(0.47-0.77)$ \\
\hline \multicolumn{3}{|l|}{ Alcohol intake } \\
\hline Never & 1.0 & 1.0 \\
\hline Monthly or less & $1.17(0.99-1.38)$ & $1.16(0.97-1.37)$ \\
\hline 2-4 times a month & $1.36(1.12-1.66)$ & $1.26(1.02-1.56)$ \\
\hline 2-3 times a week & $1.36(1.08-1.71)$ & $1.19(0.93-1.52)$ \\
\hline$\geq 4$ times a week & $1.32(1.07-1.62)$ & $1.23(0.98-1.54)$ \\
\hline \multicolumn{3}{|l|}{ Physical activity } \\
\hline Inactive & 1.0 & 1.0 \\
\hline Active & $1.30(1.14-1.47)$ & $1.22(1.05-1.42)$ \\
\hline \multicolumn{3}{|l|}{ Depression } \\
\hline No & 1.0 & 1.0 \\
\hline Yes & $0.86(0.76-0.99)$ & $1.04(0.87-1.24)$ \\
\hline \multicolumn{3}{|l|}{ Anxiety } \\
\hline No & 1.0 & 1.0 \\
\hline
\end{tabular}

Table 3 ORs (95\% Cls) for the Association Between Participant Characteristics and Receipt of the Influenza Vaccination ( $n=4,697)$ (continued)

\begin{tabular}{lll}
\hline Characteristic & $\begin{array}{l}\text { Unadjusted OR } \\
(95 \% \mathrm{Cl})\end{array}$ & $\begin{array}{l}\text { Adjusted OR } \\
(95 \% \mathrm{Cl})\end{array}$ \\
\hline Yes & $\mathbf{0 . 8 4}(\mathbf{0 . 7 4 - 0 . 9 6 )}$ & $0.94(0.79-1.12)$ \\
\hline Disability & & \\
\hline Mild & 1.0 & 1.0 \\
\hline Moderate & $0.92(0.78-1.08)$ & $0.97(0.81-1.16)$ \\
\hline Severe & $0.92(0.79-1.08)$ & $0.97(0.80-1.18)$ \\
\hline Disease duration & & \\
\hline$<\mathbf{1 0}$ & 1.0 & 1.0 \\
\hline $\mathbf{1 0 - 1 9}$ & $1.06(0.71-1.59)$ & $0.89(0.56-1.39)$ \\
\hline$\geq 20$ & $1.16(0.79-1.69)$ & $0.83(0.53-1.30)$ \\
\hline $\begin{array}{l}\text { Use of any disease-modifying } \\
\text { therapy }\end{array}$ & 1.0 & 1.0 \\
\hline No & $\mathbf{1 . 3 1 ( 1 . 1 5 - 1 . 4 8 )}$ & $\mathbf{1 . 4 1}(\mathbf{1 . 2 3 - 1 . 6 3 )}$ \\
\hline Yes & & \\
\hline
\end{tabular}

Abbreviations: $\mathrm{Cl}=$ confidence interval; $\mathrm{OR}=$ odds ratio.

C-statistic $=0.63$, Hosmer-Lemeshow goodness of fit $\chi^{2}=12.9, p=0.15$ Bold indicates statistical significance.

awareness about indications for vaccination, and misconceptions about the effects on their disease. ${ }^{15,27}$ For example, in 1 study, $18 \%$ of persons with IBD who did not get vaccinated reported not doing so because it could be harmful for their IBD. ${ }^{7}$ In the previously mentioned Israeli study, cited reasons for not getting these vaccinations included fear of non-neurologic adverse effects (72.7\%) or that their treating physician had recommended against it because of their MS (11.7\%). This latter observation highlights the potential role of physician barriers to vaccination, ${ }^{28,29}$ including gaps in knowledge about safety of and recommendations for vaccinations in specific populations.

Studies in other immune-mediated disease populations have highlighted interventions that can improve vaccination rates. For example, in an IBD clinic, a vaccine questionnaire was distributed to patients during the influenza season, and any outstanding vaccinations were offered at the visit. ${ }^{30}$ This increased uptake of the influenza vaccination from $54 \%$ in the prior year to $81 \%$ and uptake of pneumococcal vaccine in the prior 5 years from $31 \%$ to $54 \%$. This approach is potentially feasible for improving vaccinations in people with MS, too. Provider recommendation is strongly associated with uptake of the seasonal influenza vaccine ${ }^{31}$; thus, recommendations at the time of routine clinic visits may be helpful.

Study limitations should be considered. The response rate was $62 \%$, similar to the mean response rate of $60 \%$ in the medical literature. ${ }^{32}$ Responders differed with respect to 
Table 4 Reasons for Not Receiving Seasonal Influenza Vaccination ( $n=1,303$ Participants)

\begin{tabular}{lll}
\hline Reason & $\mathrm{N}(\%)$ & $95 \% \mathrm{Cl}$ \\
\hline Personal preference & $391(30.0)$ & $27.6,32.6$ \\
\hline Did not think I needed it & $339(26.0)$ & $23.7,28.5$ \\
\hline Personal choice & $24(1.84)$ & $0.01,0.03$ \\
\hline Concerns about flu efficacy & $19(1.46)$ & $0.94,2.27$ \\
\hline Misperceptions about the flu shot ${ }^{\mathrm{a}}$ & $9(0.69)$ & $0.36,1.31$ \\
\hline Side effects or illness from the vaccine & $382(29.3)$ & $26.9,31.8$ \\
\hline Concerned about side effects & $370(28.4)$ & $26.0,30.9$ \\
\hline Previous illness following flu shot & $12(0.92)$ & $0.53,1.60$ \\
\hline Access/availability & $27(2.07)$ & $1.43,3.00$ \\
\hline Too expensive & $6(0.46)$ & $0.21,1.00$ \\
\hline Difficulty accessing clinic & $9(0.69)$ & $0.36,1.31$ \\
\hline Vaccine not available & $12(0.92)$ & $0.53,1.60$ \\
\hline Contextual factors & $121(9.29)$ & $7.83,11.0$ \\
\hline Too busy/forgot & $83(6.37)$ & $5.17,7.83$ \\
\hline CovID-19 & $5(0.38)$ & $0.16,0.90$ \\
\hline Sick when flu shot available & $4(0.31)$ & $0.12,0.79$ \\
\hline Never offered flu shot & $38(2.92)$ & $2.13,3.98$ \\
\hline My doctor advised against a flu shot & $157(12.1)$ & $10.4,13.9$ \\
\hline my MS & $308(23.6)$ & $21.4,26.0$ \\
\hline Allergy to eggs/vaccines & $66(5.07)$ & $4.00,6.39$ \\
\hline Don't know & $52(3.99)$ & $3.06,5.20$ \\
\hline Other & $73(5.60)$ & $4.48,6.99$ \\
\hline & & \\
\hline
\end{tabular}

Abbreviations: $\mathrm{Cl}$ = confidence interval; $\mathrm{MS}$ = multiple sclerosis.

a Example reported reasons: "Any live vaccine because on Gilenya", "IVIG", "Ocrevus contraindicated/concerned about interaction", "No live viruses", "Told long ago never to do with MS", and "on other meds conflicted".

race, sex, age, and educational status compared with nonresponders, although some of these differences were quite small. NARCOMS participants are volunteers, creating a potential selection bias, which may limit the generalizability of our findings to the entire MS population. We relied on self-reported vaccination status; however, in a cohort with IBD, the positive predicted value of self-reported influenza vaccination was $96.7 \%$ and that of pneumococcal vaccination was $96.4 \%$. The positive predictive value of other vaccinations is lower. ${ }^{33}$ Our questionnaire asked about multiple reasons for not getting the influenza vaccination but did not explicitly ask about lack of efficacy; thus, we may have underestimated the frequency of this concern. Although we asked participants to report reasons for not obtaining the influenza vaccination, we did not capture reasons for not obtaining other optional vaccinations such as those for

\section{TAKE-HOME POINTS}

$\rightarrow$ Seasonal influenza vaccination uptake is lower than recommended among persons with multiple sclerosis (MS).

$\rightarrow$ In winter 2019/2020, seasonal influenza vaccination uptake ranged from $59.1 \%$ among persons with MS aged $18-24$ years to $79.9 \%$ for those aged $\geq 65$ years.

$\rightarrow$ The most common reasons for not getting influenza vaccine were personal preference, concerns about general adverse effects, and concerns that the vaccine would worsen MS.

$\rightarrow$ Misconceptions about the safety of vaccination in the context of MS highlight the importance of education about these issues.

hepatitis or Zoster, and these would also be important to guide policy. Study strengths included the large sample size and evaluation of a broad range of demographic factors, health behaviors, and clinical characteristics with vaccination uptake.

Vaccination uptake is lower than desired in the MS population compared with public health recommended targets, including for seasonal influenza vaccination. This places people with MS at risk for preventable infections and related hospitalizations and complications. Misconceptions about the safety of vaccination in the context of MS appear to play an important role in the choice to not obtain vaccinations, highlighting the importance of education about these issues and consistent recommendations by health care providers.

\section{Study Funding}

NARCOMS is a project of the Consortium of Multiple Sclerosis Centers (CMSC). NARCOMS is funded in part by the CMSC and the Foundation of the CMSC. The study was also supported in part by the Waugh Family Chair in Multiple Sclerosis and a Research Manitoba Chair (to R.A.M). The funding sources had no role in the study design, collection, analysis or interpretation of the data, or in the decision to submit the article for publication.

\section{Disclosure}

R.A. Marrie: receives research funding from the CIHR, MS Society of Canada, MS Scientific Research Foundation, National MS Society, Crohn's and Colitis Canada, the US Department of Defense, The Arthritis Society, Biogen Idec, Roche, and the CMSC; and is supported by the Waugh Family Chair in Multiple Sclerosis. L. Kosowan reports no disclosures relevant to the manuscript. G. Cutter: data/safety monitoring committees for AMO, BioLineRx, BrainStorm Cell Therapeutics, Galmed, Horizon, Hisun, Merck, Merck/Pfizer, OPKO Biologics, Neurim, Novartis, Orphazyme, Sanofi, 
Reata, Receptos/Celgene, Teva, NHLBI (Protocol Review Committee), and NICHD (OPRU oversight committee) and consulting/advisory boards for Biogen, Click Therapeutics, Genzyme, Genentech, GW, Klein Buendel, MedImmune, MedDay, Novartis, Osmotica, Perception Neuroscience, Recursion, Roche, Somahlution, and TG Therapeutics. RJ. Fox: consulting fees from AB Science, Actelion, Biogen, Celgene, EMD Serono, Genentech, Immunic, Novartis, Sanofi, and TG Therapeutics; advisory committees for Actelion, Biogen, Immunic, Novartis, and Sanofi; and research grant funding from Novartis. A. Salter: journal editor/member of editorial advisory board for Circulation: Cardiovascular Imaging. Full disclosure form information provided by the authors is available with the full text of this article at Neurology.org/cp.

\section{Publication History}

Received by Neurology: Clinical Practice January 29, 2021. Accepted in final form March 15, 2021.

\begin{tabular}{lll} 
Appendix Authors & \\
\hline Name & Location & Contribution \\
\hline $\begin{array}{l}\text { Ruth Ann } \\
\text { Marrie, MD, PhD }\end{array}$ & $\begin{array}{l}\text { University of Manitoba, } \\
\text { Winnipeg, Canada }\end{array}$ & $\begin{array}{l}\text { Responsible for study } \\
\text { concept and design and } \\
\text { drafting and revision of the } \\
\text { manuscript }\end{array}$ \\
\hline $\begin{array}{l}\text { Leanne } \\
\text { Kosowan, MSc }\end{array}$ & $\begin{array}{l}\text { Wninersity of Manitoba, } \\
\text { Winneg, Canada }\end{array}$ & $\begin{array}{l}\text { Conducted study analyses } \\
\text { and revision of the } \\
\text { manuscript }\end{array}$ \\
$\begin{array}{l}\text { Gary Cutter, } \\
\text { PhD }\end{array}$ & $\begin{array}{l}\text { University of Alabama at } \\
\text { Birmingham, AL }\end{array}$ & $\begin{array}{l}\text { Study concept and design } \\
\text { and revision of the } \\
\text { manuscript }\end{array}$ \\
\hline $\begin{array}{l}\text { Robert J. Fox, } \\
\text { MD, MSc }\end{array}$ & Cleveland Clinic, OH & $\begin{array}{l}\text { Study concept and design } \\
\text { and revision of the } \\
\text { manuscript }\end{array}$ \\
\hline $\begin{array}{l}\text { Amber Salter, } \\
\text { PhD }\end{array}$ & $\begin{array}{l}\text { Washington University in } \\
\text { St. Louis, MO }\end{array}$ & $\begin{array}{l}\text { Study concept and design } \\
\text { and revision of the } \\
\text { manuscript }\end{array}$ \\
\hline
\end{tabular}

\section{References}

1. Wijnands JM, Kingwell E, Zhu F, et al. Infection-related health care utilization among people with and without multiple sclerosis. Mult Scler J. 2017;23:1506-1516.

2. Montgomery S, Hillert J, Bahmanyar S. Hospital admission due to infections in multiple sclerosis patients. Eur J Neurol. 2013;20:1153-1160.

3. De Keyser J, Zwanikken C, Boon M. Effects of influenza vaccination and influenza illness on exacerbations in multiple sclerosis. J Neurol Sci. 1998;159:51-53.

4. Farez MF, Correale J, Armstrong MJ, et al. Practice guideline update summary: vaccinepreventable infections and immunization in multiple sclerosis. Neurology. 2019;93:584-594.

5. Auriel E, Gadoth A, Regev K, Karni A. Seasonal and H1n1v influenza vaccines in MS: safety and compliance. J Neurol Sci. 2012;314:102-103.

6. Marrie RA, Walld R, Bolton JM, et al. Uptake of influenza vaccination in inflammatory bowel disease, multiple sclerosis and rheumatoid arthritis: a cohort study. CMAJ Open. $2020 \cdot 9(2):$ E5 $510-E 521$.

7. Malhi G, Rumman A, Thanabalan R, et al. Vaccination in inflammatory bowel disease patients: attitudes, knowledge, and uptake. J Crohn's Colitis. 2015;9:439-444.
8. Marrie RA, Cutter G, Tyry T, Campagnolo D, Vollmer T. Validation of the NARCOMS Registry: diagnosis. Mult Scler. 2007;13:770-775.

9. Centers for Disease Control and Prevention. Behavioral Risk Factor Surveillance System Survey Questionnaire. U.S. Department of Health and Human Services; 1995.

10. Bush K, Kivlahan DR, McDonell MB, Fihn SD, Bradley KA. The Audit Alcohol Consumption Questions (audit-C): an effective brief screening test for problem drinking. Ambulatory care quality improvement project (acquip). Alcohol use Disorders identification test. Arch Intern Med. 1998;158:1789-1795.

11. Marrie RA, Goldman MD. Validity of performance scales for disability assessment in multiple sclerosis. Mult Scler. 2007;13:1176-1182.

12. Marrie RA, Salter A, Tyry T, Cutter GR, Cofield S, Fox RJ. High hypothetical interest in physician-assisted death in multiple sclerosis. Neurology. 2017;88:1528-1534.

13. Green R, Kalina J, Ford R, Pandey K, Kister I. SymptoMScreen: a tool for rapid assessment of symptom severity in Ms across multiple domains. Appl Neuropsychol Adult. 2017;24:183-189.

14. Hammami MB, Pandit P, Salamo RT, Odufalu FD, Schroeder K. Health Maintenance and vaccination of patients with inflammatory bowel disease: practice and perception of responsibility of gastroenterologists vs primary care providers. Ochsner J. 2019;19: 210-219.

15. Waszczuk K, Waszczuk E, Szenborn L. Can we better protect patients with inflammatory bowel disease against infections - patient Attitude and personal immunization knowledge. Acta Gastroenterol Belg. 2018;81:257-261.

16. Hosmer DW, Lemeshow S. Applied Logistic Regression. John Wiley \& Sons; 1989.

17. Centers for Disease Control and Prevention National Center for Immunization and Respiratory Diseases. Influenza vaccination coverage* by age group, adults 18 Years and older, United States, behavioral risk factor surveillance system (brfss), 2018-19 season. 2019. Accessed November 9, 2020, cdc.gov/flu/fluvaxview/coverage1819estimates.htm.

18. Krasselt M, Ivanov JP, Baerwald C, Seifert O. Low vaccination rates among patients with rheumatoid arthritis in a German outpatient clinic. Rheumatol Int. 2017;37(2): 229-37.

19. Subesinghe S, Rutherford AI, Ibrahim F, Harris H, Galloway J. A large two-centre study in to rates of influenza and pneumococcal vaccination and infection burden in rheumatoid arthritis in the UK. BMC Musculoskeletal Disorders. 2016;17:322.

20. Ghaderi S, Berg-Hansen P, Bakken IJ, Magnus P, Trogstad L, Haberg SE. Hospitalization following influenza infection and pandemic vaccination in multiple sclerosis patients: a nationwide population-based registry study from Norway. Eur J Epidemiol. 2020;35:355-362.

21. Lu PJ, O'Halloran A, Kennedy ED, et al. Awareness among adults of vaccinepreventable diseases and recommended vaccinations, United States, 2015. Vaccine. 2017;35:3104-3115

22. Bar-Or A, Calkwood JC, Chognot C, et al. Effect of ocrelizumab on vaccine responses in patients with multiple sclerosis: the veloce study. Neurology. 2020;95:e1999-e2008.

23. Bar-Or A, Freedman MS, Kremenchutzky M, et al. Teriflunomide effect on immune response to influenza vaccine in patients with multiple sclerosis. Neurology. 2013;81: $552-558$.

24. Olberg HK, Eide GE, Cox RJ, et al. Antibody response to seasonal influenza vaccination in patients with multiple sclerosis receiving immunomodulatory therapy. Eur J Neurol. 2018;25:527-534.

25. Kappos L, Mehling M, Arroyo R, et al. Randomized trial of vaccination in fingolimodtreated patients with multiple sclerosis. Neurology. 2015;84:872-879.

26. Farmanara N, Sherrard L, Dube E, Gilbert NL. Determinants of non-vaccination against seasonal influenza in Canadian adults: findings from the 2015-2016 influenza immunization coverage survey. Can J Public Health. 2018;109:369-378.

27. Wasan SK, Calderwood AH, Long MD, Kappelman MD, Sandler RS, Farraye FA. Immunization rates and vaccine beliefs among patients with inflammatory bowel disease: an opportunity for improvement. Inflamm Bowel Dis. 2014;20: 246-250.

28. Nichol KL, Zimmerman R. Generalist and subspecialist physicians' knowledge, attitudes, and practices regarding influenza and pneumococcal vaccinations for elderly and other high-risk patients: a nationwide survey. Arch Intern Med. 2001;161: 2702-2708.

29. Yeung JH, Goodman KJ, Fedorak RN. Inadequate knowledge of immunization guidelines: a missed opportunity for preventing infection in immunocompromised ibd patients. Inflamm Bowel Dis. 2011;18:34-40.

30. Parker S, Chambers White L, Spangler C, et al. A quality improvement project significantly increased the vaccination rate for immunosuppressed patients with ibd. Inflamm Bowel Dis. 2013;19:1809-1814.

31. Lu PJ, Srivastav A, Amaya A, et al. Association of provider recommendation and offer and influenza vaccination among adults aged $\geq 18$ years-United States. Vaccine. 2018;36:890-898.

32. Asch DA, Jedrziewski MK, Christakis NA. Response rates to mail surveys published in medical journals. J Clin Epidemiol. 1997;50:1129-1136.

33. Rolnick SJ, Parker ED, Nordin JD, et al. Self-report compared to electronic medical record across eight adult vaccines: do results vary by demographic factors? Vaccine. 2013;31:3928-3935. 


\title{
Neurology ${ }^{\circ}$ linical Practice
}

\author{
Uptake and Attitudes About Immunizations in People With Multiple Sclerosis \\ Ruth Ann Marrie, Leanne Kosowan, Gary R. Cutter, et al.
}

Neurol Clin Pract 2021;11;327-334 Published Online before print April 22, 2021

DOI 10.1212/CPJ.0000000000001099

This information is current as of April 22, 2021

\begin{tabular}{|c|c|}
\hline $\begin{array}{l}\text { Updated Information \& } \\
\text { Services }\end{array}$ & $\begin{array}{l}\text { including high resolution figures, can be found at: } \\
\text { http://cp.neurology.org/content/11/4/327.full.html }\end{array}$ \\
\hline References & $\begin{array}{l}\text { This article cites } 30 \text { articles, } 6 \text { of which you can access for free at: } \\
\text { http://cp.neurology.org/content/11/4/327.full.html\#\#ref-list- } 1\end{array}$ \\
\hline Citations & $\begin{array}{l}\text { This article has been cited by } 1 \text { HighWire-hosted articles: } \\
\text { http://cp.neurology.org/content/11/4/327.full.html\#\#otherarticles }\end{array}$ \\
\hline Subspecialty Collections & $\begin{array}{l}\text { This article, along with others on similar topics, appears in the following collection(s): } \\
\text { All epidemiology } \\
\text { http://cp.neurology.org//cgi/collection/all_epidemiology } \\
\text { Multiple sclerosis } \\
\text { http://cp.neurology.org//cgi/collection/multiple_sclerosis }\end{array}$ \\
\hline Permissions \& Licensing & $\begin{array}{l}\text { Information about reproducing this article in parts (figures,tables) or in its entirety can be } \\
\text { found online at: } \\
\text { http://cp.neurology.org/misc/about.xhtml\#permissions }\end{array}$ \\
\hline Reprints & $\begin{array}{l}\text { Information about ordering reprints can be found online: } \\
\text { http://cp.neurology.org/misc/addir.xhtml\#reprintsus }\end{array}$ \\
\hline
\end{tabular}

Neurol Clin Pract is an official journal of the American Academy of Neurology. Published continuously since 2011, it is now a bimonthly with 6 issues per year. Copyright Copyright (C) 2021 The Author(s). Published by Wolters Kluwer Health, Inc. on behalf of the American Academy of Neurology.. All rights reserved. Print ISSN: 2163-0402. Online ISSN: 2163-0933.

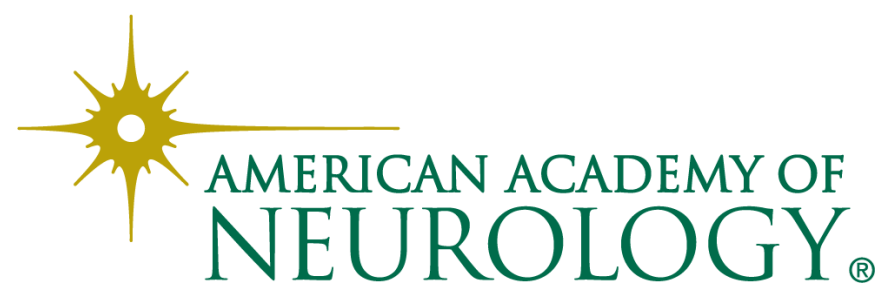

